\title{
Desempenho de telhas de escória de alto forno e fibras vegetais em protótipos de galpões
}

\author{
Maristela N. da Conceiçãa ${ }^{1}$, Sulivan P. Alves ${ }^{1}$, Aurélio Telatin Júnior ${ }^{2}$, Iran J. 0. da Silva ${ }^{3}$, \\ Sônia M. S. Piedade ${ }^{3}$, Holmer Savastano Júnior \& G ustavo Tonoli ${ }^{4}$
}

RESUMO

Busca-se, em todo o mundo, a substituição do cimento amianto por alternativas seguras para o ambiente e para a saúde do trabalhador, além de econômicas, razão por que o uso de fibras vegetais como aglomerado em países tropicais onde estes resíduos são abundantes, tem-se mostrado bastante viável. No presente experimento foram comparadas telhas de cimento amianto pintadas com tinta reflexiva, telhas cerâmicas e telhas compostas de uma matriz à base de cimento Portland CPII $32 Z$ (ABNT N BR-5735), escória de alto-forno (EAF) e sílica ativa, reforçadas com fibras de polpa celulósica de sisal (Agave sisalana). Utilizaram-se protótipos de galpões avícolas nos quais o calor produzido pelas aves foi simulado por lâmpadas incandescentes. Para caracterização do ambiente térmico lançou-se mão dos índices de conforto: ITU (índice de temperatura e umidade), ITGU (índice de temperatura de globo e umidade), CTR (carga térmica radiante) e ental pia (H) em que os resultados demonstraram que as tel has compostas apresentaram comportamento térmico semelhante ao das telhas cerâmicas, podendo ser utilizadas em substituição às telhas de cimento amianto.

Palavras-chave: telhado, conforto térmico, cimento amianto

\section{Performance of tiles composed of blast furnace slag and vegetable fiber in prototype barns}

\begin{abstract}
The substitution of cement asbestos by safer and equally economical alternatives has being searched for throughout the world. The usage of vegetal staple fiber as agglomerate in tropical countries where these residues are abundant has shown it self to be viable. In this study, roofing tiles fabricated with cement base Portland CPII $32 Z$ (ABNT NBR-5735), blast furnace slag (EAF), active silica reinforced with cellulose pulp staple fibers of sisal (Agave sisalana) were compared with cement asbestos roofing tiles with white paint and ceramic roofing tiles. Prototypes of poultry facilities were used and lamps simulated the heat produced by the birds. Indices thermal index of humidity (ITU), (Temperature indez of globe and humidity) ITGU, radiant thermal confort (CTR) and entalpy $(\mathrm{H})$ were employed for the characterization of the thermal atmospheric comfort and the results showed that the alternative roofing tiles were similar to the ceramic tiles and could be used as a substitute for asbestos roofing tiles.
\end{abstract}

Key words: roof, thermal comfort, asbestos cements

\footnotetext{
${ }^{1}$ Doutoranda ESALQ/USP, Núcleo de Pesquisa em Ambiência. Av. Pádua Dias, 11 CP: 9 CEP:13418-900, Piracicaba, SP. Fone: (19) 3447.8657. E-mail: maristel@esalq.usp.br; spalves@esalq.usp.br

2 Mestrando em Física do Ambiente Agrícola ESALQ/U SP

3 ESALQ/USP, Fone (19) 3447.8565. E-mail: ijosilva@esalq.usp.br; soniamsp@esalq.usp.br.

4 Faculdade de Zootecnia e Engenharia de Alimentos /USP. Av. Duque de Caxias Norte, 225. CEP 13635-900, Pirassununga, SP. Fone: (19) 3565.4200. E-mail: holmers@ @usp.br
} 


\section{INTRODUÇÃO}

O telhado é o fator que mais contribui para as condições do ambiente, dentro de galpões para a criação animal. O telhado influi no ambiente térmico através do material constituinte das telhas, da sua natureza superficial e da existência e eficiência de isolantes térmicos e forros. Os materiais e elementos construtivos exercem controle sobre o ambiente interno devido às suas propriedades térmicas e mecânicas. (Rodrigues, 1998). De acordo com Rivero (1986) a cobertura ideal de instalações para animais, nas condições brasileiras, deve apresentar grande capacidade de refletir a radiação solar, ter considerável capacidade de isolamento térmico e ainda capacidade de retardo térmico em torno de $12 \mathrm{~h}$. Com essas características, a pequena quantidade de radiação solar absorvida pela telha terá dificuldade em atravessar o material e, ao fazê-lo, atingirá seu interior com defasagem em torno de $12 \mathrm{~h}$, aquecendo o ambiente interior quando sua temperatura estiver mais baixa.

O tipo de material determinará a quantidade de radiação que passará para dentro da construção, contribuindo para a elevação da temperatura no seu interior; no caso dos aviários, a este calor se soma o calor latente e sensível produzido por cada ave aumentando ainda mais a carga térmica radiante e, consequentemente, a temperatura interna do ar.

Grande parte das instalações para avicultura utiliza a cobertura com telhas onduladas de cimento amianto em virtude de apresentarem custo de construção inferior ao das telhas cerâmicas devido, principalmente, ao fato da estrutura de suporte ser mais leve e empregar menor quantidade de mão-de-obra. Czarick \& Tyson (1989) demonstraram que quando pintada com pintura reflexiva, a telha de cimento amianto apresenta melhora significativa no desempenho térmico porém, em virtude dos comprovados efeitos cancerígenos na sua produção, o cimento amianto tende a ser substituído. A fabricação de telhas sem amianto a partir de matérias-primas de custo reduzido por meio de processos alternativos e em pequena escala, tem sido desenvolvida pelo Grupo de Construções Rurais da FZEA-USP em Pirassununga (Agopyan et al., 2005; Cunha et al., 2001); referidos estudos envolveram o emprego de resíduos de indústrias siderúrgicas (escória de alto-forno) como aglomerante alternativo e fibras residuais de sisal, coco e eucalipto, como reforço. $\mathrm{O}$ desempenho mecânico e físico das telhas demonstrou seu potencial para aplicação na construção rural, tanto em moradias quanto em abrigos para animais.

O desenvolvimento de pesquisas sobre instalações para avicultura em escala natural apresenta custo elevado. Modelos em escala reduzida têm sido adotados para reproduzir instalações com grande discrepância entre as dimensões horizontais e verticais, como é o caso de instalações avícolas (Sevegnani et al., 1994).

A classificação do ambiente térmico através de índices de conforto para animais possibilita determinar a adequação deste ambiente à atividade zootécnica que se pretende desenvolver. Os índices mais frequentemente utilizados são o ITU: índice de temperatura e umidade, ITGU: índice de temperatura de globo e umidade (Buffington et al., 1981) e CTR: carga térmica radiante (Esmay, 1982). Maiores valores para esses índices indicam piores condições de conforto térmico. A entalpia $(\mathrm{H})$ é uma grandeza psicrométrica que indica a quantidade de calor presente na massa de ar seco, seu valor é determinado através da temperatura do ar e da razão de mistura entre o ar seco e o úmido, sendo expressa em kJ kg-1 de ar seco. De acordo com Albrigth (1990) apud Pandorfi (2002) a entalpia pode ser utilizada para determinar as condições ambientais.

O presente trabalho teve por objetivo comparar o desempenho térmico de um tipo de telha alternativa com dois tipos de cobertura largamente utilizados no meio avícola, utilizando-se de protótipos de galpões avícolas.

\section{MATERIAL E MÉTODOS}

O experimento foi realizado em Piracicaba, SP, Brasil.

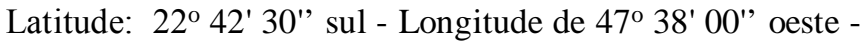
Altitude de $546 \mathrm{~m}$, no período de 31/01/2005 a 22/02/2005.

Utilizaram-se modelos em escala reduzida e distorcida (1:2 na vertical e 1:10 na horizontal) com medidas de 3,6 m de comprimento por $1,2 \mathrm{~m}$ de largura e $1,5 \mathrm{~m}$ de altura. Os modelos foram instalados sobre solo coberto de grama batatais, sendo sua estrutura de tijolos sem paredes laterais e telhado em duas águas, com comprimento no sentido leste-oeste (Figura 1).

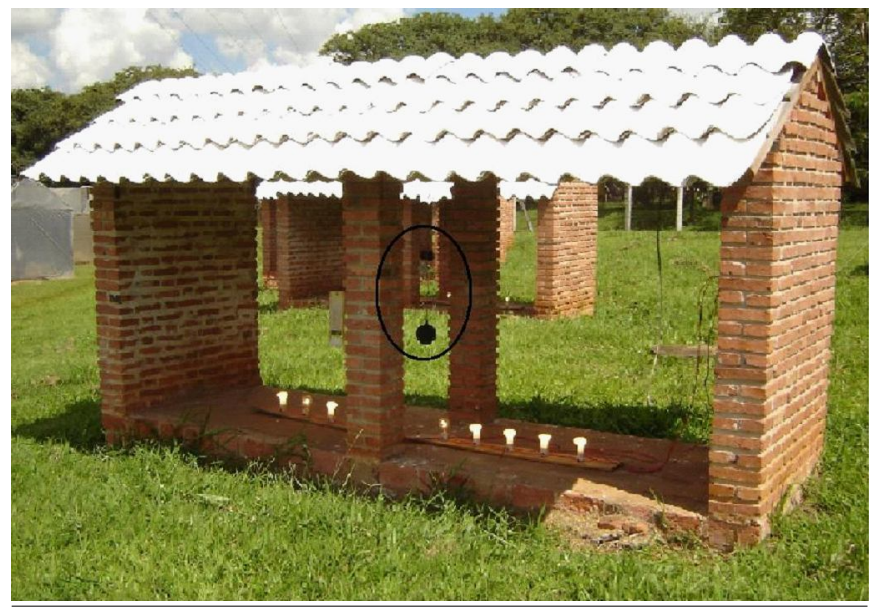

Figura 1. Vista do protótipo e localização do mini datalogger

Os materiais de cobertura utilizados foram: 1) telhas compostas de uma matriz à base de cimento Portland CPII $32 Z$ (ABNT NBR-5735) + escória de alto-forno (EAF) e sílica ativa, reforçadas com fibras de polpa celulósica de sisal (Agave sisalana) (Devito, 2003); 2) telhas de cimento amianto recém pintadas de branco e 3) telhas cerâmicas. Em cada protótipo se usaram 10 lâmpadas de $100 \mathrm{~W}$, simulando o calor sensível mais o calor latente produzido pelas aves, na proporção de $20 \mathrm{~W}$ por ave adulta $(2,1 \mathrm{~kg})$. Foram simuladas 12 aves $\mathrm{m}^{-2}$, totalizando $1036 \mathrm{~W}$. Obtiveram-se os dados climáticos por mini datalloggers da marca $\mathrm{HOBO} \circledast$ acoplados a globos negros instalados no centro geométrico dos protótipos (Figura 1); os registros foram feitos a cada $30 \mathrm{~min}$, ao 
longo das $24 \mathrm{~h}$ e os dados registrados foram: temperatura bulbo seco $\left(\mathrm{t}_{\mathrm{s}},{ }^{\circ} \mathrm{C}\right)$, temperatura do ponto de orvalho $\left(\mathrm{t}_{\mathrm{po}},{ }^{\circ} \mathrm{C}\right)$, temperatura de globo negro $\left(\mathrm{t}_{\mathrm{gn}},{ }^{\circ} \mathrm{C}\right)$ e umidade relativa (UR\%). Na estação meteorológica, situada a $30 \mathrm{~m}$ do local do experimento, registrou-se a intensidade de chuvas, a radiação solar incidente e a velocidade dos ventos. Para avaliação do ambiente térmico calcularam-se os índices de conforto:

ITU (Índice de Temperatura e Umidade).

$\mathrm{ITU}=\mathrm{ts}+0,36$ tpo $+41,2$

em que:

ts - temperatura do termômetro de bulbo seco, ${ }^{\circ} \mathrm{C}$

tpo - temperatura do ponto de orvalho, ${ }^{\circ} \mathrm{C}$

ITGU (Índice de temperatura de Globo e Umidade)

$\mathrm{ITGU}=\operatorname{tgn}+0,36$ tpo $+41,5$

em que:

tgn - temperatura do termômetro de globo negro, ${ }^{\circ} \mathrm{C}$

tpo - temperatura do ponto de orvalho, ${ }^{\circ} \mathrm{C}$

CTR (Carga Térmica Radiante)

$\mathrm{CTR}=\mathrm{t}(\mathrm{TMR})^{4}$

em que:

$\mathrm{t}$ - constante de Stefan-Boltzman $\left(5,67 \times 10^{-8} \mathrm{~W} \mathrm{~m}^{-2} \mathrm{~K}^{-4}\right)$

TMR - temperatura média radiante, $\mathrm{K}$

$\mathrm{TMR}=100\left\{\left[2,51 \mathrm{VV}^{0,5}(\mathrm{Tgn}-\mathrm{Ts})+(\mathrm{Tg} / 100)^{4}\right]^{0,25}\right\}$

Tgn - temperatura do Globo negro, $\mathrm{K}$

Ts - temperatura do bulbo seco, $\mathrm{K}$

VV - velocidade do vento, $\mathrm{m} \mathrm{s}^{-1}$

Calculou-se, também, a entalpia externa $(\mathrm{H})$ para se determinar o dia, no período estudado, em que este índice foi maior sendo considerado o dia de maior desconforto.

$\mathrm{H}=1,006 \mathrm{ts}+\mathrm{W}(2501+1,805 \mathrm{ts})$

em que:

ts - Temperatura de bulbo seco, ${ }^{\circ} \mathrm{C}$

$\mathrm{W}$ - $\left(0,622 \times\right.$ ea) $\times \mathrm{P} \mathrm{atm}^{-1}$ Razão de mistura, $\mathrm{kPa}$

ea -(UR $x$ es) $\times 100^{-1}$

es $-0,6108 \mathrm{x}$ e $\mathrm{e}^{(17,3 \mathrm{ts}) / 237,3+\mathrm{ts})}, \mathrm{kPa}$

UR - Umidade relativa, \%

Patm - adotou-se $94 \mathrm{kPa}$ para região de Piracicaba

O delineamento experimental utilizado foi de blocos ao acaso; utilizou-se o GLM do SAS® para se efetuar as análises, sendo tratamento os tipos de telhas, blocos os dias e a variáveis respostas: $\mathrm{t}_{\mathrm{s}}, \mathrm{t}_{\mathrm{go}}$, UR\%, ITU, ITGU e CTR; determinou-se, ainda se houve interação entre tratamentos e horas do dia.

\section{RESULTADOS E DISCUSSÃO}

Na Tabela 1 são apresentados os resultados do teste de Tukey para as grandezas térmicas.
Tabela 1. Resultados do teste de Tukey para médias diárias nos três tratamentos

\begin{tabular}{|c|c|c|c|c|c|c|}
\hline Tratamento & ţ $\left({ }^{\circ} \mathrm{C}\right)$ & $t_{\text {yn }}\left({ }^{\circ} \mathrm{C}\right)$ & UR $\%$ & ITU & ITGU & CTR $\left(\mathrm{W} \mathrm{m} \mathrm{m}^{-2}\right)$ \\
\hline Telha composta & $25,389 \mathrm{~A}$ & $26,677 \mathrm{~B}$ & $59,447 \mathrm{~A}$ & $72,179 \mathrm{~A}$ & $73,467 \mathrm{~B}$ & $474,641 \mathrm{~B}$ \\
\hline Cimento amianto & $25,502 \mathrm{~A}$ & $25,405 \mathrm{C}$ & 56,537 B & 71,973 B & $71,876 \mathrm{C}$ & $449,174 \mathrm{C}$ \\
\hline Telha cerâmica & $24,410 \mathrm{~A}$ & $26,823 \mathrm{~A}$ & $59,709 \mathrm{~A}$ & $72,294 \mathrm{~A}$ & 73,707 A & $477,740 \mathrm{~A}$ \\
\hline
\end{tabular}

Médias seguidas da mesma letra na coluna não diferiram entre si a nível de 5\% de significância pelo teste de Tukey

Observando-se a Tabela 1, não se constata diferença estatística para temperatura de bulbo seco, o que se previa, uma vez que todos os protótipos estão sob a mesma condição ambiental e no mesmo período. A temperatura de globo apresentou diferença estatística $(\mathrm{P}<0,05)$ por se tratar de um parâmetro que indica a carga térmica do ambiente. No presente estudo a melhor condição (menor temperatura de globo) foi encontrada sob a cobertura de telhas de cimento amianto pintada de branco, seguida da telha composta por fibra vegetal e o pior desempenho foi apresentado pela telha cerâmica. Este fato pode ser explicado em razão das telhas de cimento amianto terem recebido uma camada de tinta branca imediatamente antes do início da pesquisa, demonstrando assim que o efeito da refletividade da tinta branca foi superior ao efeito da transmissividade das telhas cerâmicas, evento este observado também por Czarick \& Tyson (1989).

O cimento amianto apresentou menor valor de ITU, que foi significativamente diferente dos demais em função do referido tratamento ter apresentado valor menor para umidade relativa, o que não se conseguiu explicar, uma vez que todos os protótipos eram abertos e estavam em situação semelhante.

Em relação ao ITGU, o resultado foi semelhante aos encontrados para temperatura de globo, em que os três tratamentos diferiram entre si. As telhas de fibra vegetal mostraram, quando comparadas com as telhas cerâmicas, valores inferiores, indicando menor capacidade de retenção de calor interno e menor transmissão do calor da parte externa para a interna.

Os resultados médios de CTR indicaram que o cimento amianto novamente apresentou os menores valores, confirmando a eficiência da pintura branca na redução da carga térmica dentro das instalações, uma vez que Kawabata et al. (2005) encontraram, quando trabalharam com telhas compostas de fibras vegetais comparadas com telhas de cimento amianto sem pintura, menores valores de CTR para as telhas composta de fibras. De acordo com Frota \& Schiffer (1995) o uso de pintura branca nas telhas de cimento-amianto promove uma reflexão dos raios solares, de cerca de 70 a $88 \%$, dependendo da natureza da tinta. Quando a comparação é feita entre os tratamentos telha composta e telha cerâmica, a telha composta apresenta valores significativamente menores, embora mais próximos que as telhas de cimento amianto pintadas de branco.

A Figura 2A apresenta os valores médios horários de CTR obtidos no decorrer de todo o período experimental. Comparando-se a telha cerâmica com a telha composta de fibras vegetais, verificou-se um cruzamento entre as curvas estabelecidas a partir das médias obtidas para os dois materiais nos horários de maior insolação (entre 10 e 16 h), fato este comprovado pela existência de interação significativa entre os tratamentos e as horas do dia para esses horários específicos, o 


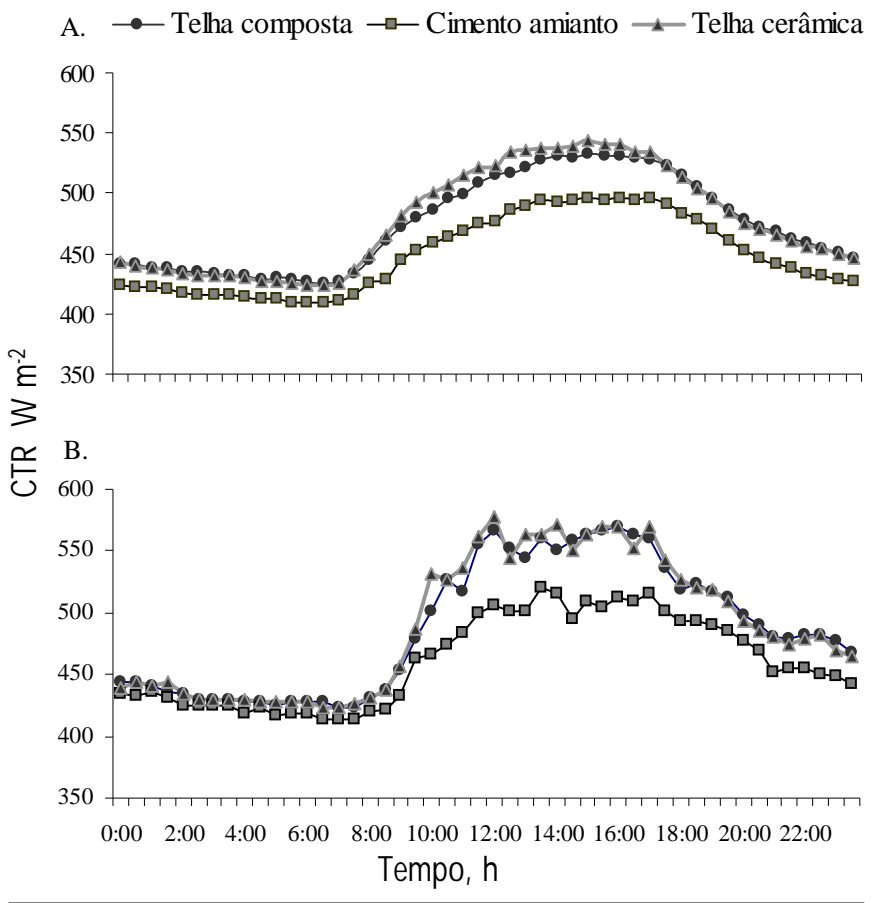

Figura 2. Curvas de CTR durante 0 dia: (A) média dos valores de CTR no período experimental; (B) valores de CTR para o dia de maior entalpia no período

que sugere uma inércia térmica maior da telha composta de fibras vegetais quando comparadas com as telhas cerâmicas.

Na Figura 2B se observa os valores de CTR para um único dia, ou seja, o dia considerado de maior entalpia e, consequentemente, o dia de condições mais desconfortáveis.

Dentro do período estudado o dia de maior entalpia teve como valor médio $\mathrm{H}=70,23 \mathrm{~kJ} \mathrm{~kg}^{-1}$ de ar seco, o que de acordo com Barbosa Filho et al. (2006), pode ser considerado um ambiente desconfortável para as aves em terminação. A Figura 2B ilustra, para este dia, o que a comparação de médias da CTR mostrou para o período como um todo. A telha de cimento amianto pintado apresentou melhor desempenho em todos os horários enquanto as telhas compostas de fibras vegetais e a telha cerâmica tiveram desempenho semelhante. A capacidade reflexiva da tinta branca contribuiu para que houvesse menor absorção e, em consequiência, também menor transmissão do calor para o interior da instalação. As telhas compostas de fibras vegetais são mais escuras que as de cimento amianto e mais claras que as telhas cerâmicas e têm tamanho e espessura intermediários entre as telhas cerâmicas e as de amianto. A associação dessas duas características fez com que apresentassem comportamento térmico bastante semelhante ao das telhas cerâmicas; estas, por sua vez, são mais escuras, porém proporcionam entrada de ar nos encaixes e menor capacidade de transmissão de calor em função do material que as constitui. No período noturno o calor interno (armazenado + produzido pelas lâmpadas) foi idêntico nos três tratamentos e o valor de CTR encontrado foi muito semelhante, indicando que a capacidade de dissipação dos três materiais foi a mesma.

\section{CONCLUSÕES}

1. As telhas compostas de fibras vegetais apresentaram desempenho térmico semelhante as das telhas cerâmicas apontadas como referência, quanto ao conforto térmico em instalações.

2. A confecção das telhas compostas com fibras vegetais é segura para o trabalhador, diferentemente das telhas de cimento amianto.

\section{LITERATURA CITADA}

Agopyan, V.; Savastano Jr., H.; John, V. M.; Cincotto, M. A. Developments on vegetable fibre-cement based materials in São Paulo, Brazil: An overview. Cement \& Concrete Composites, v.27, p.527-536, 2005.

Barbosa Filho, J. A. D.; Silva, M. A. N.; Vieira, F. M. C.; Silva, I.J.O. Avaliação direta e prática. Avicultura Industrial, v.4, n.1144, p.54-57, 2006.

Buffington, D. E.; Collazo-Arocho, A.; Canton, G. H.; Pitt, D.; Thatcher, W. W.; Collier, R.J. Black globe-humid index (BGHI) as comfort equation for dairy cows. Transactions of ASAE, v.24, p.711-14, 1981

Cunha, L; Savastano Jr., H.; Miasiro, H. Y. Fabricação de telhas de argamassa de cimento portland com adição de escória de alto forno. In: Congresso Brasileiro de Engenharia Agrícola, 30, 2001, Foz do Iguaçu. Anais....Foz do Iguaçu: SBEA, 2001. p.1-4.

Czarick, M.; Tyson, B. L. Reflective roof coating. Poultry International, v.23, n.8, p.26-32, 1989.

Devito R. A. Estudos físicos e mecânicos de telhas de cimento de escória de alto-forno reforçados com fibras celulósicas residuais. São Carlos: EESC/USP. 2003. 63p. Dissertação Mestrado

Esmay, M. L. Principles of animal environment 2.ed. Westport: AVI Publishing Company Inc, 1982. 325p

Frota, A.; Schifer, S. R. Manual de conforto térmico. 2.ed., São Paulo: Studio Nobel, 1995. 243p.

Kawabata, C. Y.; Castro, R. C.; Savastano Jr., H. Índices de conforto térmico e respostas fisiológicas de bezerros da raça holandesa em bezerreiros individuais com diferentes coberturas. Engenharia Agrícola, v.25, n.3, p.598-607, 2005.

Pandorfi, H. Avaliação do comportamento de leitões em diferentes sistemas de aquecimento por meio da análise de imagem e identificação eletrônica. Piracicaba: ESALQ/USP, 2002. 89p. Dissertação Mestrado

Rivero, R. Arquitetura e clima: Acondicionamento térmico natural. Porto Alegre: Luzzato Editores Ltda, 1986. 240p.

Rodrigues, E. H. V. Desenvolvimento e avaliação de um sistema de resfriamento evaporativo, por aspersão intermitente, na cobertura de aviários usando modelos de escala distorcida. Campinas: FEAGRI/UNICAMP, 1998. 178p. Tese Doutorado

Sevegnani, K. B; Ghelfi Filho, H.; Silva, I. J. O. Comparação de vários materiais de cobertura através de índices de conforto térmico. Scientia Agricola, v.51, n.1, p.1-7, 1994. 